\title{
Evaluation of SAR Reduction for Mobile Phones Using RF Shields
}

\author{
L.K. Ragha \\ SIES Graduate School of Technology, \\ Nerul, Navi Mumbai 400706, India.
}

\author{
M.S.Bhatia \\ Bhabha Atomic Research Centre \\ Mumbai 400085, India.
}

\begin{abstract}
In this paper we propose to attach radio frequency (RF) shields on mobile phone to reduce Specific Absorption Rate (SAR) in the spherical head model. Shields made of ferrimagnetic materials are used to suppress surface currents on the mobile phone. Many kinds of simulation are performed to investigate the effect of various parameters like location, size, shape and thickness of the shield on the SAR and also on the antenna performance using the field simulation software, CSTMicrowave studio (MWS).Paper includes numerical evaluation of the SAR reduction in the spherical head model and also analyzes the SAR data for shielding effectiveness.
\end{abstract}

\section{Keywords}

SAR, SRF, Mobile phone, Radiation pattern, Ferrimagnetic materials, RF shields.

\section{INTRODUCTION}

Mobile phone safety remains a topic of growing public concern. There are two issues concerning mobile phone safety. The first is that of non-thermal biological effects. These effects are related to the amount of RF energy deposited in the tissue - RF dosimeter [1]. The second is that of computational RF dosimetry. Computer simulation is used to estimate the deposition of RF energy, the SAR, in the head of a user. The SAR [2] in the human head is defined as $S A R=\frac{\sigma|E|^{2}}{\rho} w / k g$

Where $\sigma$ is the electrical conductivity of tissue, $\mathrm{E}$ is the rms magnitude of the electric field strength vector at a given point in the head model, and $\rho$. is the mass density of tissue. The SAR is normally used to evaluate the degree of the hazard to the human body. As per the FCC, ANSI/IEEE and Safety code 6 standards the recommended SAR values are $0.08 \mathrm{~W} / \mathrm{Kg}$ for a Whole body and $1.6 \mathrm{~W} / \mathrm{Kg}$ for over any 1 gram of tissue. Because live human heads can not be safely experimented for these measurements, computational RF dosimetry provides the best estimate of SAR in actual human heads. There is a need to develop techniques for reducing SAR in the design stage of mobile phone to meet exposure standards [3].

One way of reducing SAR in the human head is by attaching RF shield made of a ferrimagnetic material to the front side of the mobile phone [4].The mechanism behind reduction of SAR is due to the suppression of surface currents on the front side of mobile phone box. When an electromagnetic wave (EMW) traveling through free space encounters a different medium, the wave will be reflected, transmitted and/or absorbed. EMW absorption materials absorb the energy in electromagnetic waves as magnetic loss, and convert that energy, in the end, to heat. The effectiveness of the RF shielding can be specified in terms of an SAR reduction factor (SRF) and is defined as follows [5]:

$$
\begin{aligned}
& S R F_{1 g}(\%)=\frac{S A R_{1 g}-S A R_{1 g, s}}{S A R_{1 g}} \times 100 \\
& S R F_{10 g}(\%)=\frac{S A R_{10 g}-S A R_{10 g, s}}{S A R_{10 g}} \times 100
\end{aligned}
$$

Where $S R F_{1 g}$, is $\mathrm{SRF}$ for $1 \mathrm{~g}$ peak $\mathrm{SAR}, S R F_{10 g}$, is $\mathrm{SRF}$ for $10 \mathrm{~g}$ peak SAR, $S A R_{1 g}$ is $1 \mathrm{~g}$ peak SAR (without RF shielding), $S A R_{1 g, s}$ is $1 \mathrm{~g}$ peak SAR (with RF shielding), $S A R_{10 g}$ is $10 \mathrm{~g}$ peak $\mathrm{SAR}$ (without RF shielding), and $S A R_{10 g, s}$ is $10 \mathrm{~g}$ peak $\mathrm{SAR}$ (with RF shielding), respectively. It is observed that lager SRF value implies greater shielding effectiveness.

In this paper, the effect of various parameters like location, size, shape, and thickness of the RF shield on the SAR and the antenna performance are investigated by using the field simulation software, CST-MWS. Results have shown that SAR and SRF values change with the above mentioned parameters. There is no degradation of the radiation pattern but there is a slight variation in return loss with the use of RF shields. Simulation results will be useful for compliance testing of mobile phones.

\section{MATERIALS}

In our study, two tissue human head model is used. The radius of bone tissue is $10 \mathrm{~cm}$ and that of brain tissue is $9 \mathrm{~cm}$. The mobile phone shown in figure 1 was modeled as a perfect electric conductor (PEC) box, having external dimensions $2.5 \times 4.0 \times$ $12.0 \mathrm{~cm} \quad(X \times Y \times Z)$. A $\lambda / 4$ cylindrical monopole antenna of $900 \mathrm{MHz}$ mounted on the top of the hand set box with $0.045 \mathrm{~cm}$ radius is used as the radiating source. The monopole is also made by PEC. The $0.25 \mathrm{~cm}$ gap is provided between top surface of the mobile phone box and cylindrical monopole. The antenna is fed at the junction between the monopole and the box. Monopole is excited by Gaussian pulse using discrete port. Literature survey revealed that mobile 
phones as explained above are still in use in some part of the world, therefore it is used for our study.

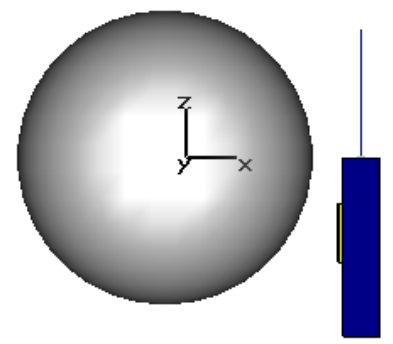

Figure1 (a) Model of human head and Mobile phone with RF shield attachment

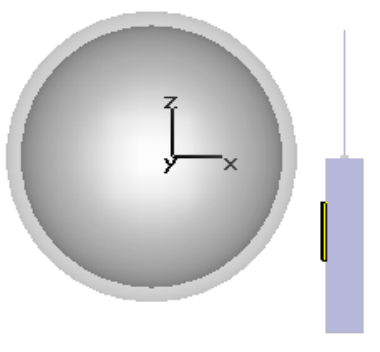

(b) Human head Model indicating two tissues.
An RF shield with a height of $\mathrm{h} \mathrm{cm}$, a width of $4 \mathrm{~cm}$ and a thickness of $\mathrm{t} \mathrm{cm}$ is attached to the front surface of mobile phone box to evaluate SAR reduction. The mobile phones with different shapes of RF shield are shown in figure 2.

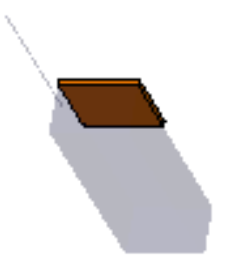

Shape-1

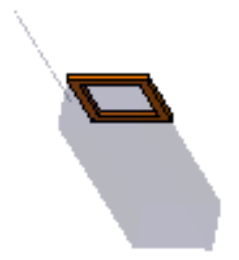

Shape-3

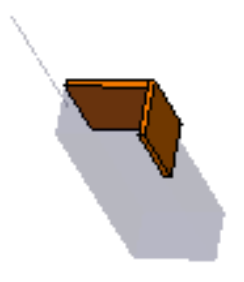

Shape-2

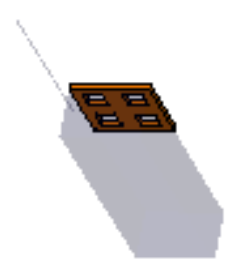

Shape-4
Figure 2. Different shapes of RF shield

\subsection{Ferrimagnetic Material}

The most important group of ferrimagnetic materials is the ferrites. In ferrites the conductivity is low which results in much smaller induced currents in the material when electromagnetic waves are applied. Also when an electromagnetic wave hits ferrite particles, the magnetic field part of the wave is cancelled [6].

Ferrites are ceramic materials with the general chemical formula $\mathrm{MOFe}_{2} \mathrm{O}_{3}$, Where MO is one or more divalent metal oxides blended with iron oxide. The iron oxide magnetite $\left(\mathrm{Fe}_{3} \mathrm{O}_{4}\right)$, the nickel-zinc ferrite $\left(\mathrm{Ni}_{1 / 2} \mathrm{Zn}_{1 / 2} \mathrm{Fe}_{2} \mathrm{O}_{4}\right)$, the Manganese -zinc ferrite and the nickel ferrite $\left(\mathrm{NiFe}_{2} \mathrm{O}_{4}\right)$ are examples of this class of materials. Manganese -zinc ferrites have the highest permeabilities [6].

The dielectric parameter $\left(\varepsilon_{r}, \sigma, \mu_{r}, \rho, \sigma_{1}=\omega \varepsilon_{0} \varepsilon_{r}{ }^{\prime \prime}\right.$

=Electrical conductivity, $\sigma_{2}=\omega \mu_{0} \mu_{r}^{\prime \prime}=$ Magnetic conductivity) values for modeling and simulation of RF shield, mobile phone and spherical head model at $900 \mathrm{MHz}$ are as listed in Table1.

Table 1. Summary of dielectric parameters

\begin{tabular}{|l|c|c|c|c|}
\hline Material & $\varepsilon_{r}$ & $\mu_{r}$ & $\begin{array}{c}\text { Conductivity } \\
\sigma \\
(\mathrm{s} / \mathrm{m})\end{array}$ & $\begin{array}{c}\text { Density } \\
\rho \\
\left(\mathrm{g} / \mathrm{cm}^{3}\right)\end{array}$ \\
\hline Air & 1 & 1 & 0 & 1 \\
\hline $\begin{array}{l}\text { Simulating } \\
\text { Brain at } \\
900 \mathrm{MHz}\end{array}$ & 55 & 1 & 1.23 & 1.03 \\
\hline $\begin{array}{l}\text { Simulating } \\
\text { Bone at } \\
900 \mathrm{MHz}\end{array}$ & 8 & 1 & 0.105 & 1.85 \\
\hline $\begin{array}{l}\text { RF shield } \\
\text { at 900 } \\
\text { MHz 7. }\end{array}$ & 2.0-j0.6 0 & $\sigma_{1}=0.030042$ & 5.27 \\
\hline PEC & & $\sigma_{2}=23450.18$ & \\
\hline
\end{tabular}

\section{METHOD}

The commercial field simulation tool, CST Microwave Studio [7]... [10], which is based on the Finite Integration technique (FIT) was used to model RF shield, the mobile phone and the spherical head for evaluating the SAR reduction.

The basic parameters used for the simulation are as mentioned below:

The Perfect boundary approximation is used for spatial discretization. The mesh is produced by an automatic mesh generator, which ensures a good compromise between accuracy and simulation time.

Mesh properties used during simulations:

Mesh type: Hexahedral; Lines per wave length: 18; Lower mesh limit: 10; Mesh line ratio: 1.8; Minimum mesh step: 5; Maximum mesh step: 15; Mesh cells: 48544, an "add space", boundary condition representing the electromagnetic wave propagating towards the outer space is set.

Solver Type: Transient solver with following settings is employed.

Excited discrete port: 1; Excitation duration: $1.777274 \mathrm{e}^{-03} \mu \mathrm{s}$; steady state accuracy limit: $-30 \mathrm{~dB}$; Maximum number of time steps: 2764; Time step width: $1.285788 \mathrm{e}^{-05} \mu \mathrm{s}$; Number of processors used: 01.

Two centimeter separation is assumed between the spherical head and a mobile phone. The antenna output power used for the simulation is 0.5 watt $(\mathrm{rms})$. To See the effect of SAR reduction in the spherical head, the ferrite material that has electric and magnetic losses ( $\left.\varepsilon_{r}=7.0-j 0.6, \mu_{r}=2.8-\mathrm{j} 3.3\right)$ is used as RF shield [5]. The antenna output power is defined as; $p_{\text {out }}=p_{a b s}+p_{s}+p_{\text {rad }}$ where $p_{a b s}$ is the power absorbed in the head model with a volume of $v_{h}, p_{s}$ is the power 
dissipated in the RF shield with a volume of $v_{s}$ and $p_{\text {rad }}$ is the power radiated to the far-field.

\subsection{SAR Reduction Mechanism}

Before deriving the SAR reducing effects using RF shield, the mechanism of SAR reduction [11] is discussed. For a monopole antenna mounted on a conducting box, the conducting box acts as a part of the antenna. The current flowing onto the conducting box spreads on all box surfaces. The local SAR on the head surface is roughly proportional to the squared surfacecurrent-density on the box. Current density on the conducting box can be suppressed by attaching RF shield on to it which in turn reduces the corresponding surface SAR.

\section{RESULTS AND ANALYSIS}

The results discussed in this section are the effect of various parameters like location, size, shape, and thickness of the RF shield on the SAR, the return loss (S11) and the far-field radiation pattern of the monopole antenna. Table 2 indicates the SAR(rms) value and $S_{11}$ (return loss in $\mathrm{db}$ ) when no RF shield is attached on to the front side of conducting box. Analysis of SAR and SRF given below is based on the results from Figure3-Figure8.Higher SRF indicates greater SAR reduction effect.

\begin{tabular}{|c|c|c|c|c|c|c|}
\hline $\begin{array}{l}S_{11} \\
(\mathrm{db})\end{array}$ & \multicolumn{2}{|c|}{$\begin{array}{c}\text { Maximum } \\
\text { SAR(w/kg) } \\
1 \mathrm{gm} \\
10 \mathrm{gm} \\
(\mathrm{rms})\end{array}$} & $\begin{array}{c}\text { Total } \\
\text { SAR(w/kg) } \\
(\mathrm{rms})\end{array}$ & $\begin{array}{l}\text { Power } \\
(\mathrm{rms})\end{array}$ & & \\
\hline $\begin{array}{c}- \\
7.10\end{array}$ & 0.50562 & 0.35031 & 0.0209922 & 0.1101 & -- & -- \\
\hline
\end{tabular}

TABLE2. LOCAL SAR VALUES ON THE HEAD SURFACE WITHOUT RF SHIELD

\subsection{SAR Reduction Based on Location of RF Shield}

To determine the location where the maximum surface current occurs, four locations of RF shielding attachment were assumed. The attaching location shown in Fig. 1 was named as location-1 in which the RF shield with $3 \mathrm{~mm}$ thickness, $4.0 \mathrm{~cm}$ width and $3.0 \mathrm{~cm}$ height was attached from $\mathrm{z}=--0.1$ to $--3.1 \mathrm{~cm}$, then for location- 2 from $\mathrm{z}=--3.1 \mathrm{~cm}$ to- $-6.1 \mathrm{~cm}$, for location $-3 \mathrm{z}$ $=--6.1 \mathrm{~cm}$ to-- $9.1 \mathrm{~cm}$ and for location $-4 \mathrm{z}=--9.1 \mathrm{~cm}$ to $--12.1 \mathrm{~cm}$. Figure 3 and Figure 4 indicate the relationship between the attaching location of RF shield and SAR and also SRF, the attaching location-2 has resulted in the maximum reduction for the SAR (i.e. SRF of $10.09 \%$ for $1 \mathrm{gm}$ sample and $7.22 \%$ for $10 \mathrm{gm}$ sample) which corresponds to maximum surface-currentdensity on the box. This result imply that only suppressing the maximum current on the front side of conducting box contributes enough to the reduction of SAR.

\subsection{SAR Reduction based on size of RF Shield}

The size of RF shield with $3 \mathrm{~mm}$ thickness, $4.0 \mathrm{~cm}$ width is changed by changing height $\mathrm{h}$ (in $\mathrm{z}$ - direction) from 1 to 11 $\mathrm{cm}$ in steps of $1 \mathrm{~cm}$. Figure 5 and Figure 6 shows the effect of size of RF shield on SAAR and SRF.SAR decreases with increase in size of ferrite sheet. Where as SRF increases with increase in size of ferrite sheet. As can be seen, RF shield with size $4 \times 8 \mathrm{~cm}^{2}$ is sufficient to get maximum SRF i.e. SRF of $16.47 \%$ for $1 \mathrm{gm}$ sample and $14.03 \%$ for $10 \mathrm{gm}$ sample.

\subsection{SAR Reduction based on shape of RF Shield}

In order to analyze the SAR and SRF data for different shapes, four shapes of RF shield with $3 \mathrm{~mm}$ thickness, $4.0 \mathrm{~cm}$ width and $4.0 \mathrm{~cm}$ height as shown in figure 2 are attached on to the top front surface of the mobile phone. In Figure 7, for shape1 it is observed that SAR values are lower for $1 \mathrm{gm}$ sample and $10 \mathrm{gm}$ sample. There is no significant reduction in SAR with shape 2.SAR values are higher in shape 3 compared to shape1.SAR values in case of shape 4 are lowest among all shapes for $1 \mathrm{gm}$ sample and for $10 \mathrm{gm}$ sample. Thus SAR reducing effect with RF shield of shape 4 is found to be more effective.

\subsection{SAR Reduction based on thickness of RF Shield}

RF shield of size $4.0 \times 4.0 \mathrm{~cm}^{2}$ is attached on to the front top surface of mobile phone. Shield thickness is varied from $0.5 \mathrm{~mm}$ - 16mm.Figure 8 shows the effect of shield thickness variation on SAR. SAR obtained was highest for a thickness of $6 \mathrm{~mm}$.

\subsection{Return Loss $\left(\mathrm{S}_{11}\right)$}

Figure9 shows the return loss $\left(\mathrm{S}_{11}\right)$ of the antenna as a function of the RF shield shape, location and size. It is observed that return loss do not change much as compared to without shield.

\subsection{Radiation Pattern}

Results have shown that attachment of RF shield on mobile phone not only reduces SAR in head model but also the radiated power. The point of concern here is whether suppression of surface current affects the radiation pattern. It is clear from figure 10 that no degradations in the radiation pattern with RF shield was observed as compared to without shield.

A personal computer with following configuration is used for computing simulations:

$\begin{array}{ll}\text { CPU } & : \text { Pentium IV }, 3 \mathrm{GHz} \\ \text { RAM Memory } & : 504 \mathrm{MB}\end{array}$

Operating System : Windows XP-Ver. 2002 


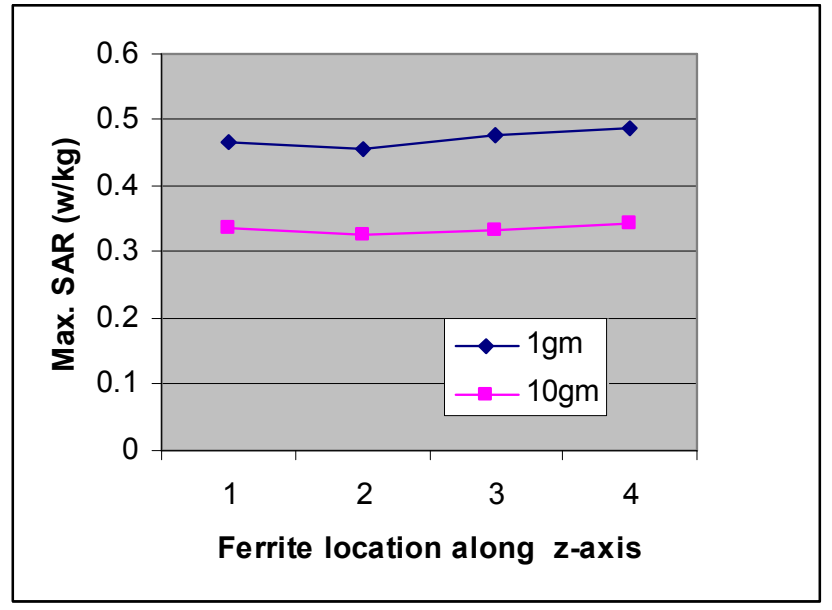

Figure 3. Variation of Max. SAR with ferrite location along zaxis.

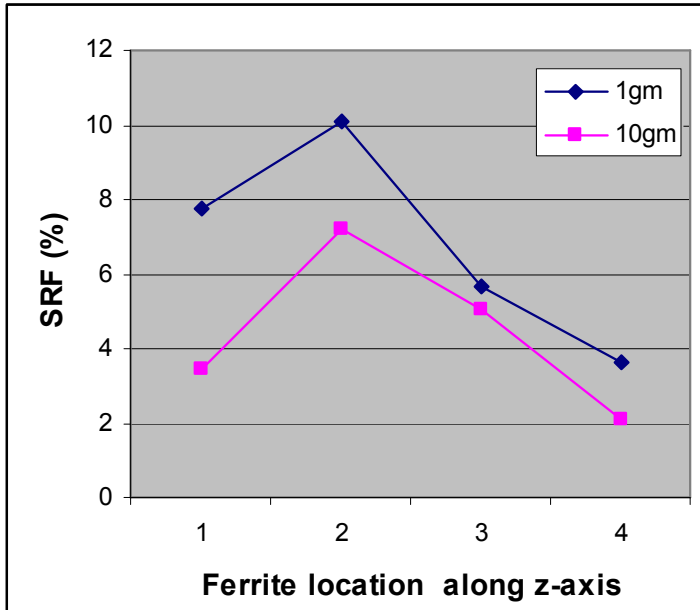

Figure 4. Variation of SRF (\%) with ferrite location along $\mathrm{z}-$ axis.

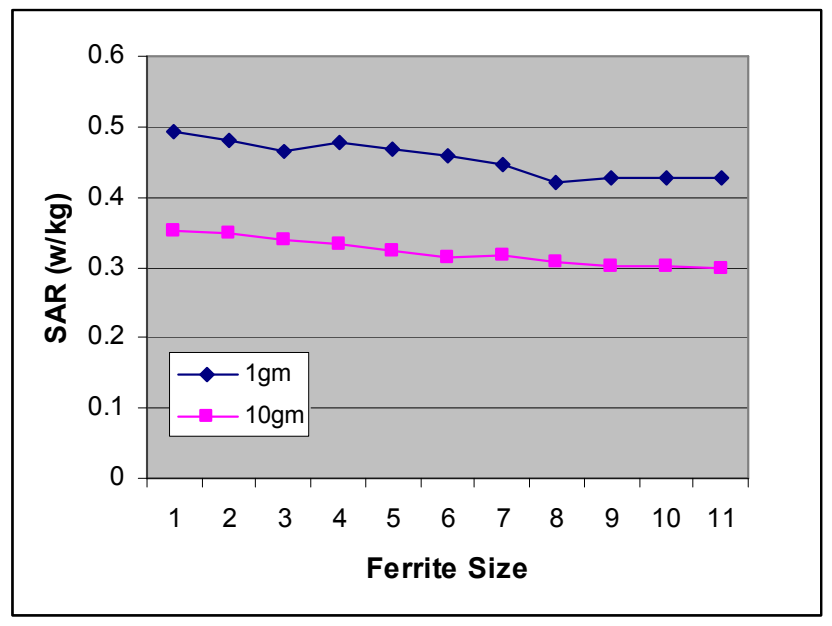

Figure 5. Variation of SAR with ferrite size along z-axis.

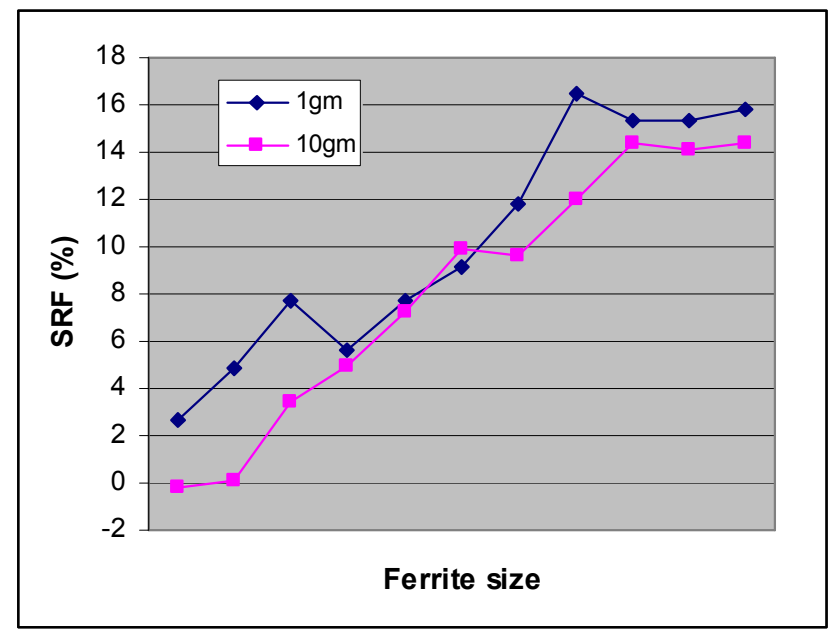

Figure 6. Variation of SRF (\%) with ferrite size along z-axis.

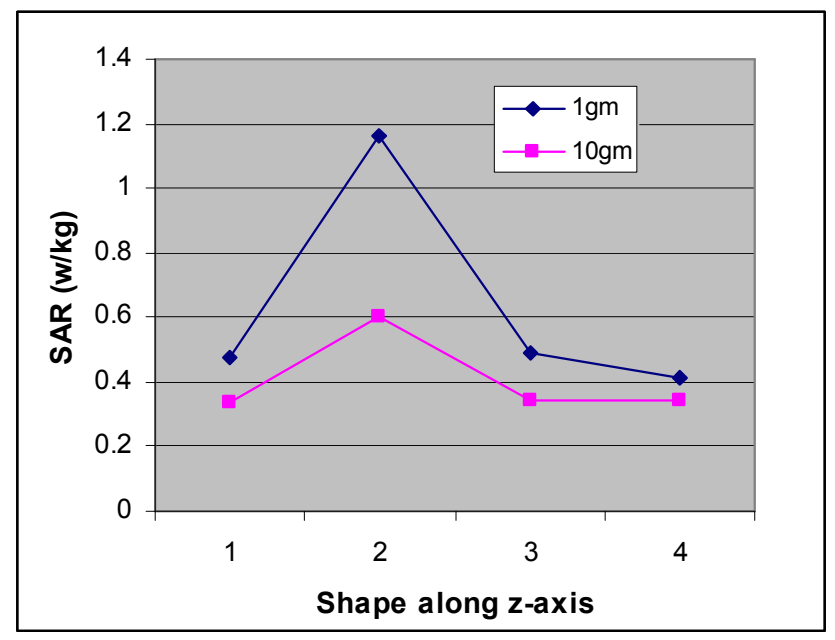

Figure 7. Variation of SAR with ferrite shape along z-axis.

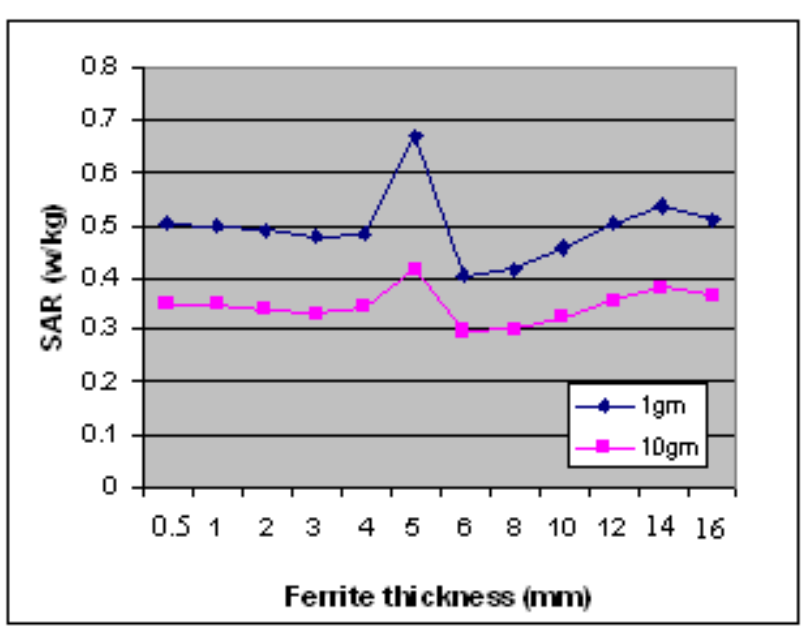

Figure 8. Variation of SAR with ferrite thickness along $\mathrm{z}$-axis. 


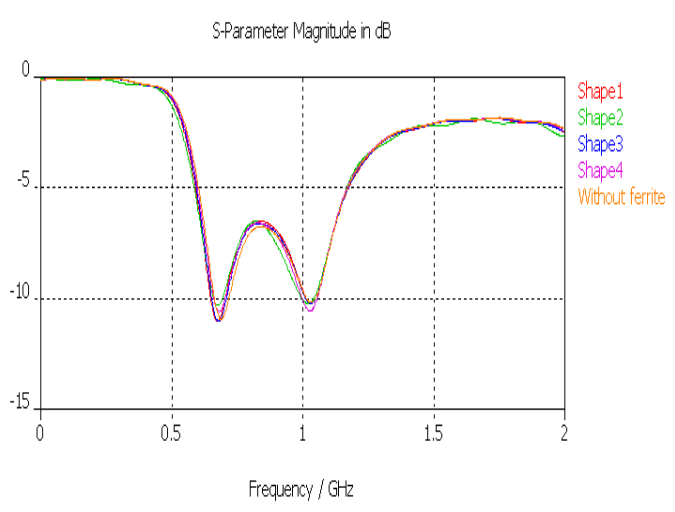

(a) S11 for different shapes of RF shield

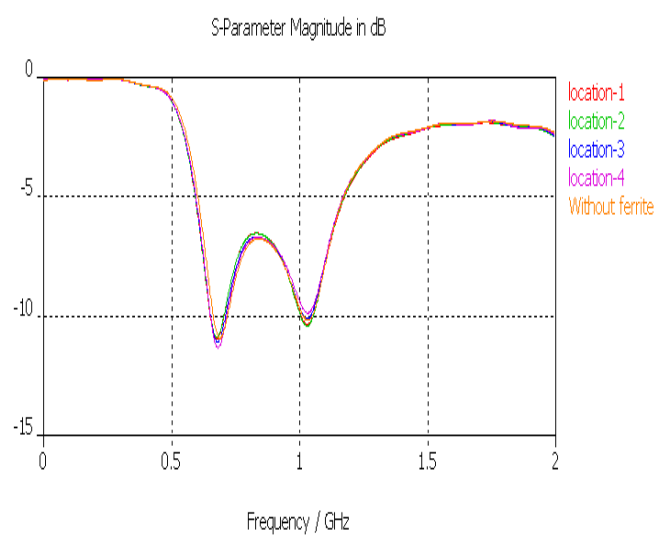

(b) S11 for different locations of RF shield

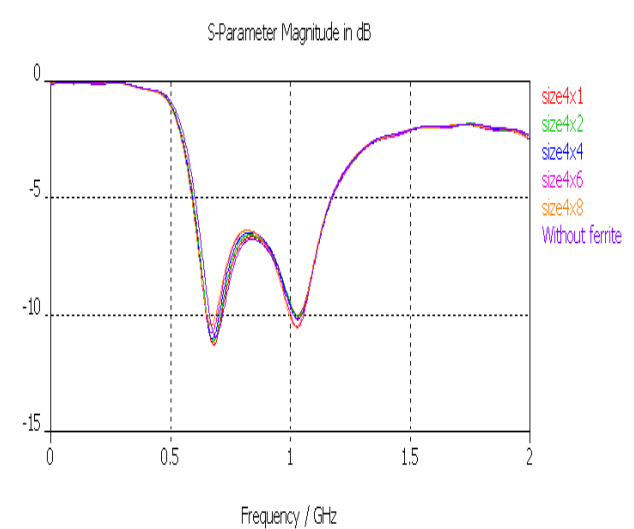

(c) S11 for different sizes of RF shield

Figure 9 Return loss (S11) of 900MHz Mobile phone antenna due to the spherical head model for different parameters of RF shield.

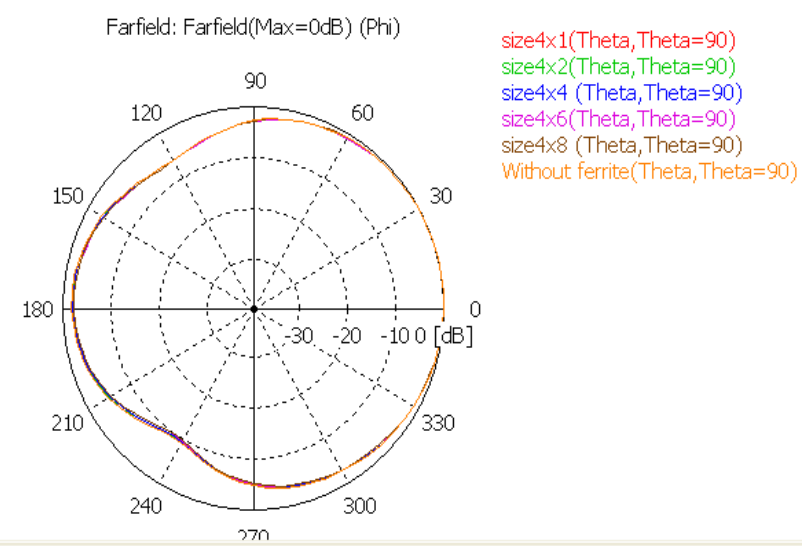

(a) Azimuth pattern (db)

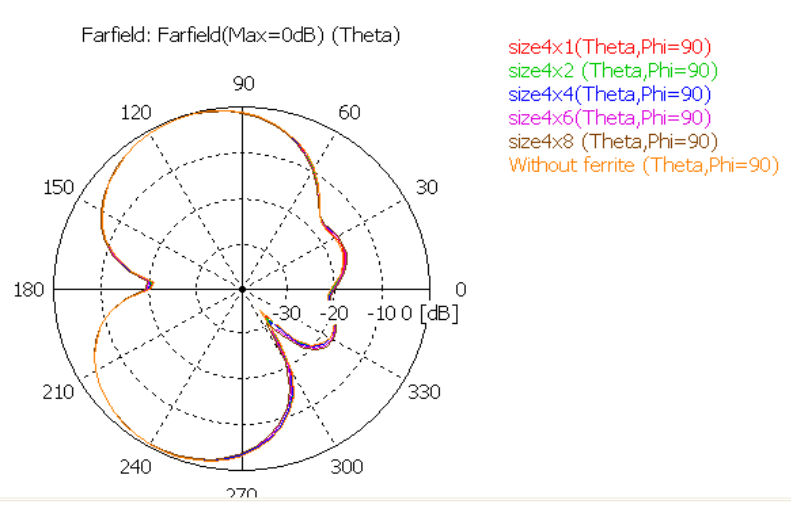

(b) Elevation pattern (db)

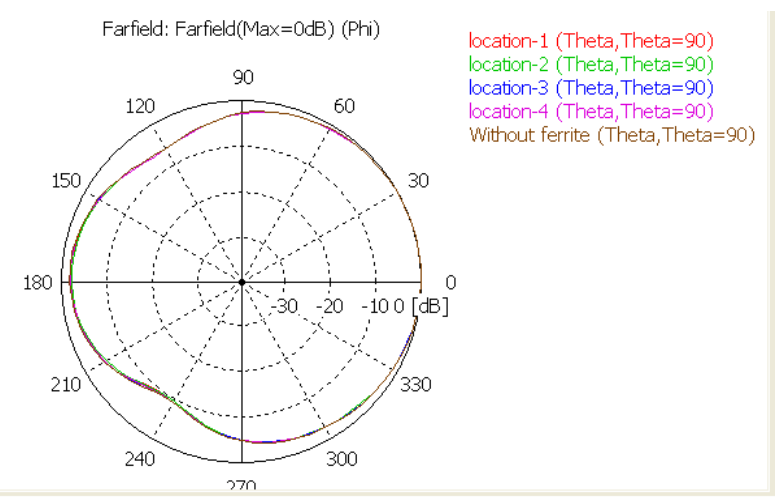

(c) Azimuth pattern (db) 


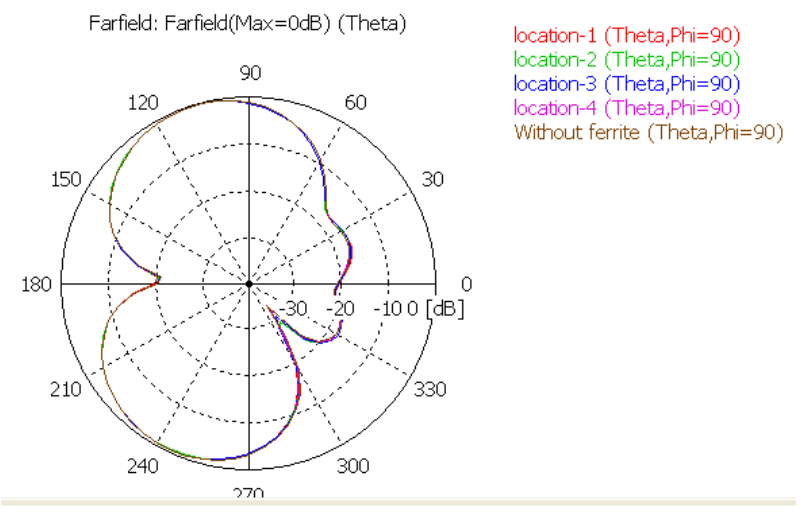

d) Elevation pattern (db)

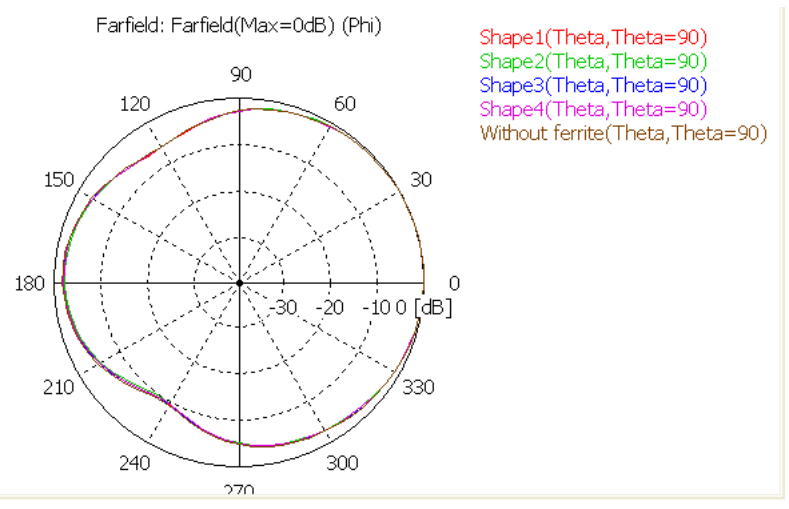

(e) Azimuth pattern (db)

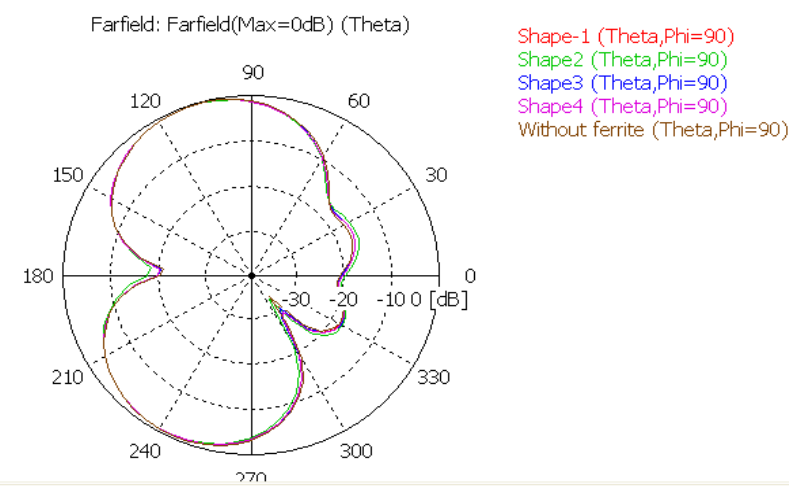

(f) Elevation pattern (db)

Figure 10. $900 \mathrm{MHz}$ radiation pattern of mobile phone antenna due to the spherical head model

\section{CONCLUSIONS}

In the present study various simulations are carried out in order to evaluate SAR reduction in the Spherical head model by attaching RF shield on to the front surface of mobile phone. The relationship between the attaching location, size, shape, thickness of RF shield and SAR reducing effect have been studied numerically by using field simulation software, CST MWS. Figure3 and Figure4 show that attaching location-2 has resulted in the maximum reduction for the SAR. Figure5 and Figure6 reveal that SAR is decreased with increase in ferrite size. In Figure7, it is observed that SAR reducing effect with RF shield for shape4 is shown to be more effective. Figure 8 shows the effect of shield thickness variation on SAR. SAR obtained was maximum for a thickness of $5 \mathrm{~mm}$. Moreover, the RF shielding does not degrade the antenna performance. However there is slight variation in return losses when compared with RF shielding. So the RF shielding gives an option for compliance testing of mobile phones at the design stage.

\section{ACKNOWLEDGMENTS}

The authors would like to thank Mr.Handu.V.K, Head, Vacuum Physics and Instrumentation Division, BARC, Mumbai and his colleagues for technical support.

\section{REFERENCES}

[1] Lin JC: Cellular Mobile Telephones and Children. IEEE Antennas and Propagation Magazine.2002, 44(5):142-145.

[2] Jung Minseok \& Lee Bomson, 'Evaluation of SAR Reduction for Mobile Communication Handsets', IEEE Antennas and Propagation Society International Symposium, Vol. 1, pp. 444-447, June 2002.

[3] A.D. Tinniswood, C.M. Furse and O.P. Gandhi," Computations of SAR distributions from two anatomically based models of the human head using CAD files of commercial telephones and the parallelized FDTD code", IEEE Trans. Antennas Propagat., 01.46n, o.6,pp.829-833, June 1998.

[4] J.Wang and 0. Fujiwara, "Reduction of electromagnetic absorption in the human head for portable telephones by a ferrite sheet attachment", IEICE Trans. Commun., vol.E80B, no.12, pp.1810-1815, Dec. 1997.

[5] Minseok Jung, Bomson Lee, "Evaluation of SAR reduction for mobile communication hand sets", IEEE APS, vol.1, pp 444-448, 2002.

[6] Johann Pretorius, "Design and Manufacture of a Ferrimagnetic Wave Absorber for Cellular Phone Radiations", IEEE 0-7803-8574-8/04/\$20.00 @), pp 119122, 2004.

[7] CST user's manual, HP Design and analysis; CST MICROWAVE STUDIO ® 4-Getting started.

[8] CST user's manual, CST MICROWAVE STUDIO ${ }^{\circledR}$ 5Advanced Topics.

[9] CST user's manual, CST MICROWAVE STUDIO ${ }^{\circledR}$ Tutorials.

[10] CST STUDIO SUIT ETm2006 User's Manual; http://www.cst.com

[11] J. Wang and O. Fujiwara, "Reduction of SAR in human head by suppression of surface currents due to a portable telephone", Proc. 13th Int. Zurich Symp. on Electromagn. Compat., Switzerland, Feb., 1999, pp.59-62. 